\title{
Unit of Equivalent Weight
}

National Cancer Institute

\section{Source}

National Cancer Institute. Unit of Equivalent Weight. NCI Thesaurus. Code C48585.

A unit of relative amount of a substance that combines with or displaces 8.0 grams of oxygen or 1.008 gram of hydrogen. The unit is usually expressed in grams and is equal to the amount of substance that gains or loses one mole of electrons in a redox reaction, or to the amount of substances that releases or accepts one mole of hydrogen ions in a neutralization reaction; or to the amount of electrolyte that carries one mole of positive or negative charge. This is a large unit and measurements are more often done in its derivatives, e.g. in milliequivalents. 